\title{
FLUTUAÇÃO POPULACIONAL DE Spodoptera frugiperda (J. E. SMITH), Diatraea saccharalis (FABRICIUS) E Doru luteipes (SCUDDER) EM MILHO CONVENCIONAL E TRANSGÊNICO Bt
}

\author{
LAÍS FERNANDA DE ARAÚJO무, ALESSANDRO GUERRA DA SILVA ${ }^{1}$, \\ IVAN CRUZ ${ }^{2}$, EDUARDO LIMA DO CARMO ${ }^{1}$, ADALBERT HORVATH NETO ${ }^{1}$, \\ MARIA MIRMES PAIVA GOULART ${ }^{1}$ e JUREMA FONSECA RATTES ${ }^{1}$
}

\begin{abstract}
${ }^{1}$ Universidade de Rio Verde, Rio Verde, GO, Brasil, laisf_agro@hotmail.com,silvaag@yahoo.com.br, eduardo@fesurv.br, adalberthorvathy@hotmail.com,mirmes.pg@hotmail.com,rattes@fesurv.br

${ }^{2}$ Embrapa Milho e Sorgo, Sete Lagoas, MG, Brasil,ivancruz@cnpms.embrapa.br
\end{abstract}

Revista Brasileira de Milho e Sorgo, v.10, n.3, p. 205-214, 2011

\begin{abstract}
RESUMO - O surgimento de tecnologias para o controle de pragas na cultura do milho deve ser analisado periodicamente, para a adoção nas regiões produtoras desse cereal. O objetivo deste trabalho foi avaliar a flutuação populacional de Spodoptera frugiperda (J. E. Smith) (Lepidoptera: Noctuidae), Diatraea saccharalis (Fabricius) (Lepidoptera: Pyralidae) e do predador Doru luteipes (Scudder) (Dermaptera: Forficulidae) em cultivo de milho convencional e Bt. O ensaio foi conduzido na safrinha, em Rio Verde, GO, com delineamento experimental de blocos casualizados, com 24 repetições. Foram empregados os híbridos P 3041 e P 3041YG, com população de 50.000 plantas.ha ${ }^{-1}$. Quantificaram-se o número de insetos e os danos provocados pelas lagartas nas folhas, colmo e pendão, quantificação e presença de internódios com galerias, altura de plantas e da inserção de espiga, massa de grãos por espiga e rendimento de grãos. O híbrido de milho P 3041 YG sofreu menor ataque de S. frugiperda e apresentou maior massa de grãos por espiga e maior rendimento de grãos em relação ao híbrido convencional P 3041.
\end{abstract}

Palavras-chave: Zea mays, controle biológico, inimigo natural, safrinha, transgênico.

\section{POPULATION DYNAMICS OF Spodoptera frugiperda (J. E. SMITH), Diatraea saccharalis (FABRICIUS) AND Doru luteipes (SCUDDER) IN CONVENTIONAL AND Bt TRANSGENIC MAIZE}

\begin{abstract}
New technologies to pests control in maize should be periodically reviewed for adoption in the cereal producing regions. This study aimed to evaluate the population dynamics of Spodoptera frugiperda (J. E. Smith) (Lepidoptera: Noctuidae), Diatraea saccharalis (Fabricius) (Lepidoptera: Pyralidae) and the predator Doru luteipes (Scudder) (Dermaptera: Forficulidae) in the development of conventional and $B t$ transgenic maize. The trial was set up in the off-season cultivation in Rio Verde, GO, Brazil. The experimental design was the randomized blocks with 24 repetitions. The hybrids P 3041 and P 3041YG were used, with a population of 50,000 plants.ha ${ }^{-1}$. It were evaluated the number of insects and the damages caused by the caterpillars on the leaves, stems and tassel, quantification and presence of internodes with galleries, plant height and insertion of ear, grain mass per ear and grain yield. The results allowed concluding that the hybrid P 3041 YG showed lower damage of $S$. frugiperda and presented higher grain mass of ear and grain yield compared to the P 3041 conventional hybrid.
\end{abstract}

Keywords: Zea mays, biological control, natural enemies, off-season cultivation, transgenic.

Versão impressa ISSN 1676-689X / Versão on line ISSN 1980-6477 http://www.abms.org.br 
O milho (Zea mays L.) é uma importante cultura na alimentação humana e animal, sendo que, no Brasil, esse cereal é cultivado na safra de verão e na safrinha. Um dos fatores comprometedores do rendimento do milho em safrinha é a incidência de insetos-praga, cujas populações têm aumentado a cada safra, prejudicando o rendimento das lavouras e, consequentemente, causando prejuízos ao produtor rural (Fernandes \& Carneiro, 2006).

Dentre os insetos-praga mais importantes da cultura do milho, destaca-se a lagarta-do-cartucho Spodoptera frugiperda (J. E. Smith) (Lepidoptera: Noctuidae), cujos danos estendem-se por todos os estádios de desenvolvimento da planta, principalmente após a formação do cartucho, onde o inseto se aloja, prejudicando a eficácia do controle químico. Estimase que a redução nos rendimentos causados pela praga seja de 15 a 34\% (Cruz \& Turpin, 1983; Cruz, 1995; Figueiredo et al., 2006a).

Outro inseto-praga de importância econômica na cultura do milho é Diatraea saccharalis (Fabricius) (Lepidoptera: Pyralidae), conhecida como broca-da-cana. Semelhante à lagarta-do-cartucho, ocorre praticamente durante todo o período de desenvolvimento do cereal. Lagartas recém-eclodidas alimentam-se de tecidos foliares e, posteriormente, penetram no interior do colmo do milho, construindo galerias e causando obstrução de seiva nos vasos condutores da planta (Cruz, 2007).

Em cultivos de milho, geralmente são realizadas aplicações frequentes de inseticidas químicos sintéticos, visando reduzir os danos provocados por $S$. frugiperda e $D$. saccharalis (Moscardi \& Souza, 2002). Entretanto, quando aplicados de maneira indiscriminada, esses produtos podem levar à ressurgência, surtos de pragas secundárias e/ou seleção de populações de insetos resistentes (Diez-Rodríguez \& Omoto, 2001). Para minimizar tais problemas, torna-se necessário desenvolver técnicas para a adoção em programas de Manejo Integrado de Pragas (MIP), com ênfase no uso de inimigos naturais (Fernandes \& Carneiro, 2006).

Neste contexto, o emprego de plantas de milho $B t$, resistentes ao ataque de insetos, constitui alternativa de proteção para minimização de perdas causadas por pragas (Maagd et al., 2001). Os genes introduzidos nas plantas transgênicas de milho codificam a expressão da proteína $B t$, permitindo ação inseticida, a qual é efetiva no controle de lepidópterospraga, como S. frugiperda, Helicoverpa zea (Boddie) (Lepidoptera: Noctuidae) e D. saccharalis (Huang et al., 2002), dentre outras. Cultivares de milho convencionais e transgênicos $(B t)$, de mesmo ciclo e porte, devem ser semeados na mesma época (Waquil et al., 2008). Esse procedimento propicia uma área de refúgio, que tem como finalidade evitar o efeito de resistência de insetos, devido ao cruzamento das diferentes populações.

Mesmo com o uso de todas as táticas de controle de pragas, tem aumentado cada vez mais a importância do manejo adequado do sistema de produção, visando a preservação dos inimigos naturais presentes nas lavouras de milho (Figueiredo et al., 2009). Para o controle de $S$. frugiperda, Doru luteipes (Scudder) (Dermaptera: Forficulidae), conhecida como "tesourinha", tem-se apresentado como predador eficiente dessa praga, sendo observada sua presença em lavouras de milho na safra de verão e na safrinha (Picanço et al., 2003). Fêmeas de D. luteipes colocam, em média, 25 ovos, e as ninfas e adultos são capazes de se alimentar de $S$. frugiperda no campo, consumindo, em média, 21 ovos ou 13 lagartas pequenas. Naqueles locais onde o milho é cultivado 
durante todo o ano, esse inimigo natural é encontrado em mais de $70 \%$ das plantas, e uma única tesourinha por planta é capaz de manter a população de lagarta do cartucho abaixo do nível de dano econômico (Cruz, 1995).

O objetivo deste trabalho foi avaliar a flutuação populacional de $S$. frugiperda, $D$. saccharalis e do inimigo natural $D$. luteipes, em cultivos de milho convencional e $B t$, em condições de safrinha, na região do Sudoeste Goiano, além das características agronômicas dessas cultivares.

\section{Material e Métodos}

O ensaio foi conduzido no município de Rio Verde, GO, Brasil (17²7’23,9”S; 5057’33,8”W; e $750 \mathrm{~m}$ de altitude), na safrinha, após a colheita da soja, em solo classificado como Latossolo Vermelho distrófico, de textura média, cultivado em sistema de plantio direto.

Empregou-se o delineamento de blocos casualizados com 24 repetições, utilizando os híbridos de milho isogênicos P 3041 (convencional) e o transgênico P 3041YG (gene CRY 1Ab da bactéria Bacillus thuringiensis), ambos caracterizados como triplos, precoces e de grãos alaranjados-duros. As parcelas foram constituídas por 20 linhas de $5,0 \mathrm{~m}$ de comprimento, espaçadas $0,5 \mathrm{~m}$ entre si. A área útil foi obtida considerando as duas linhas centrais, desconsiderando $0,5 \mathrm{~m}$ de cada extremidade. A distância de cultivo dos híbridos foi de 3,0 m.

Os híbridos foram semeados no dia 20 de fevereiro de 2009, com população de 50.000 plantas.ha $^{-1}$. Sete dias antes da semeadura, foi realizada a dessecação das ervas daninhas, utilizando o equivalente a $1.080 \mathrm{~g}$ i.a. $\mathrm{ha}^{-1}$ de equivalente ácido do herbicida glyphosate, acrescido de 806 g do 2,4-D.ha-1 ${ }^{-1}$ com volume de calda de 1501. ha $^{-1}$. No momento da semeadura, foi empregado o equivalente a $500 \mathrm{~kg} \cdot \mathrm{ha}^{-1}$ do fertilizante $02-20-18$. Não foram efetuados tratamentos de sementes e aplicação de inseticidas e fungicidas durante o desenvolvimento das plantas de milho. No início do desenvolvimento do milho, não foram constatados problemas na emergência das plântulas que pudessem comprometer a população de plantas. $\mathrm{O}$ controle das plantas daninhas foi realizado por meio de duas capinas manuais, nos primeiros trinta dias após a emergência.

As avaliações da população de adultos de $S$. frugiperda e D. saccharalis foram realizadas em intervalos de dois dias, empregando-se duas armadilhas deltas, posicionadas entre o cultivo dos híbridos. A instalação das armadilhas foi realizada na altura equivalente das plantas de milho, quando as mesmas se encontravam com três folhas completamente desenvolvidas. Uma das armadilhas continha feromônio sintético para $S$. frugiperda e a outra uma fêmea adulta de $D$. saccharalis aprisionada em gaiola. $\mathrm{O}$ piso de ambas as armadilhas apresentava papel adesivo, para fixação das mariposas. Os insetos aprisionados foram quantificados e, posteriormente, retirados das mesmas. A substituição do feromônio foi efetuada a cada 10 dias e as fêmeas de $D$. saccharalis substituídas uma vez por semana, de acordo com trabalhos realizados por Cruz et al. (2010a; 2010b).

Foram realizadas seis avaliações para $S$. frugiperda e D. luteipes. Em cada parcela, retiraramse dez plantas escolhidas aleatoriamente, sendo quantificados o número de insetos e o dano provocado pelas lagartas nas folhas e no pendão. As avaliações foram efetuadas anotando-se a porcentagem de plantas com dano no cartucho (qualquer tipo de lesão e intensidade da mesma), adotando escala visual de dano de 0 (planta sem dano) a 9 (plantas com quase 
todas as folhas destruídas), segundo escala visual adaptada de Davis et al. (1992). As folhas foram cuidadosamente removidas, para permitir a contagem das lagartas e do inimigo natural.

A avaliação referente à $D$. saccharalis foi efetuada após as plantas de milho terem atingido estádio de maturidade fisiológica. Foram coletadas dez plantas por parcela, escolhidas aleatoriamente, abrindose o colmo para quantificação de internódios totais e com galerias, bem como a sua respectiva dimensão. Simultaneamente a essa avaliação, foram determinadas a altura de plantas (medida de dez plantas do colo até o ápice do pendão, em metros) e da inserção de espigas (medida do colo até a inserção da última espiga, em metros), número de internódios totais e de espigas, massa de grãos por espiga (g) e rendimento de grãos (debulha das espigas das plantas da área útil, com posterior pesagem dos grãos, com correção para 13\% de umidade, expressando os resultados em kg.ha-1).

Os resultados obtidos foram submetidos à análise de variância e as médias comparadas pelo teste de $\mathrm{t}$, a $5 \%$ de probabilidade.

\section{Resultados e Discussão}

O monitoramento realizado com armadilhas durante o desenvolvimento das plantas de milho permitiu observar a presença de mariposas de $S$. frugiperda e $D$. saccharalis, destacando-se maior população da primeira espécie em março (Figura 1). Isso se deve, possivelmente, ao fato de que, nesse mês, há o cultivo de extensas áreas de milho safrinha na região sudoeste do Estado de Goiás, que favorece o maior número de ciclos reprodutivos do inseto (Milano et al., 2008).

Apesar de constatada a presença de mariposas ao longo das avaliações, observou-se pequena infestação de lagartas, o que, consequentemente, proporcionou baixo número de plantas atacadas (Tabela 1). Em ambos os híbridos, a supressão de $S$. frugiperda pode ser justificada pelo aumento constante do inimigo natural $D$. luteipes, principalmente a partir do início do mês de abril (Figura 2). Esse inseto necessita de ovos e lagartas de instares iniciais para se alimentar, mantendo a praga abaixo do nível de dano econômico, demonstrando a eficiência do controle biológico para S. frugiperda (Farias et al., 2001; Figueiredo et al., 2006b).

Os resultados obtidos permitem constatar a regulação natural da população de $S$. frugiperda $\operatorname{por} D$. luteipes (Figuras 1 e2). Nesse contexto, deve ser levada em consideração a presença dos insetos antes de se adotar qualquer medida de controle para $S$. frugiperda na cultura do milho. Devem ser observadas, também, as condições climáticas, pois temperaturas elevadas $\left(30^{\circ} \mathrm{C}\right)$ interferem negativamente no desenvolvimento de D. luteipes, sendo a mais favorável em torno de $25^{\circ} \mathrm{C}$ (Pasini et al., 2010). Ressalta-se que, na região Sudoeste de Goiás, ocorre redução da temperatura média até a colheita do milho safrinha, a partir do mês de abril, favorecendo, dessa forma, a ocorrência desse inimigo natural.

Nas avaliações de danos de $S$. frugiperda nas plantas de milho, pôde-se observar que, independente da época de avaliação, houve menor dano no híbrido Btem relaçãoà cultivar convencional (Tabela 1). Fato semelhante ocorreu para o dano no pendão. Dessa forma, é possível inferir que plantas de milho $B t$ apresentam maior tolerância ao ataque de $S$. frugiperda, proporcionando menores danos nas folhas, que são de extrema importância para a realização dos processos fotossintéticos e de evapotranspiração, e capazes de interferir no potencial produtivo do milho (Sangoi et al., 


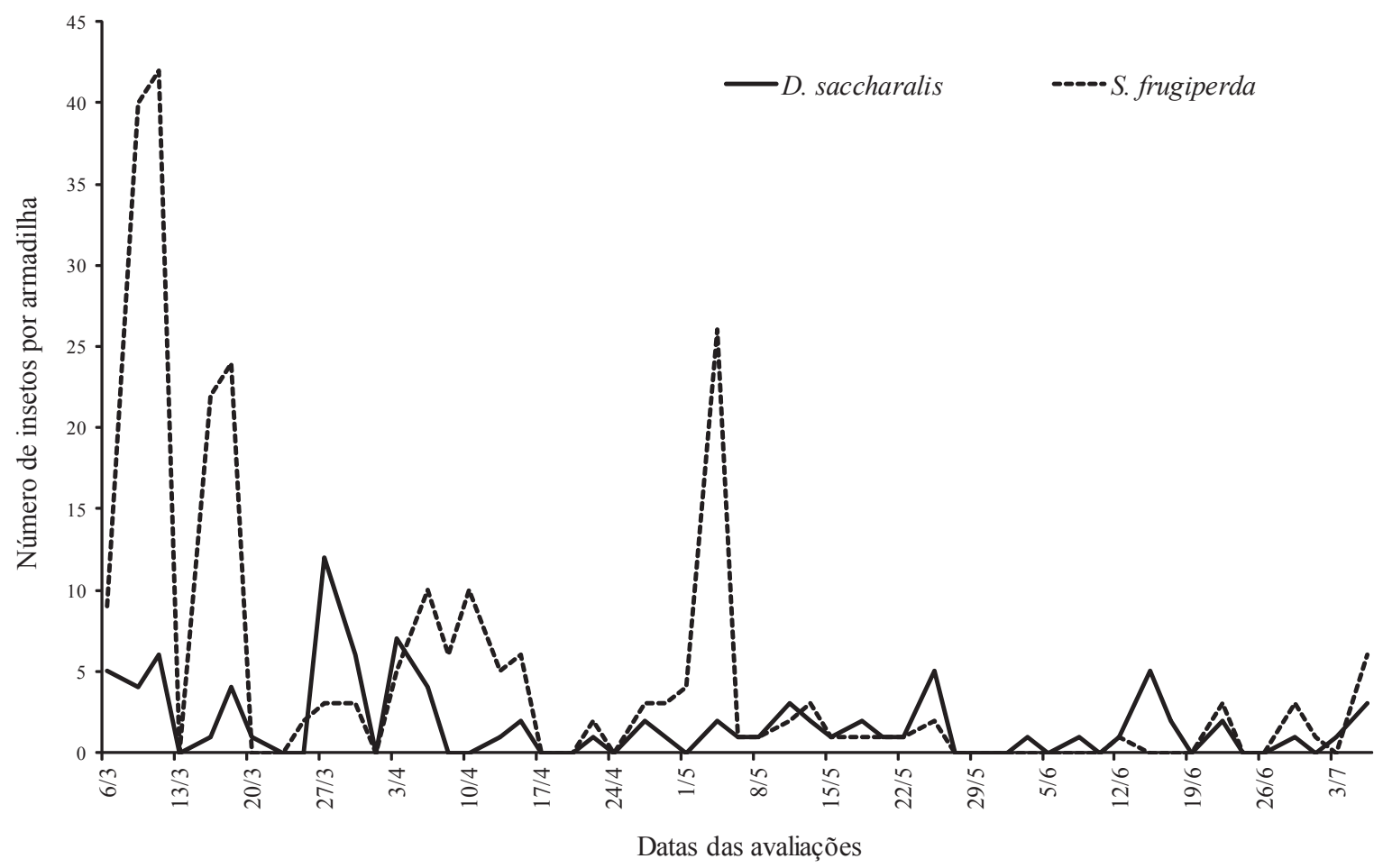

FIGURA 1. Número de adultos de $S$. frugiperda e de $D$. saccharalis capturados nas armadilhas localizadas próximas às plantas dos híbridos de milho $\mathrm{P} 3041$ e $\mathrm{P}$ 3041YG cultivados na safrinha de 2009, em Rio Verde, GO.

2007). Os resultados obtidos são semelhantes aos de outros trabalhos de pesquisa (Fernandes et al., 2003; Castro et al., 2009), os quais comprovaram que genótipos de milho $B t$ são menos atacados pela $S$. frugiperda, principalmente na fase inicial de desenvolvimento do milho. Além disso, os híbridos de milho Bt reduzem a sobrevivência e o desenvolvimento das lagartas de $S$. frugiperda, porém havendo diferenças na redução da área foliar pelo ataque da praga em função do híbrido (Waquil et al., 2002). Nesse trabalho, o híbrido que expressava a toxina Cry $1 \mathrm{~F}$ foi mais resistente ao ataque da lagarta e os que expressaram a toxina Cry $1 \mathrm{Ab}$ comportaram-se como moderadamente resistentes.
A população de $S$. frugiperda apresentou picos durante o cultivo dos híbridos (Figura 1). Esse aumento na população da praga promoveu um incremento na população do predador $D$. luteipes (Figura 2). Fato semelhante foi constatado por Guerreiro et al. (2003), que observaram a presença do predador $D$. luteipes de forma abundante em todas as fases fenológicas do milho, reduzindo, assim, a população de $S$. frugiperda.

Ressalta-se também que o cultivo do milho $B t$ não influenciou a população de $D$. luteipes, não constatando diferenças entre os híbridos utilizados em todas as épocas analisadas (Tabela 2). Resultados semelhantes foram obtidos por Fernandes et al. (2007), constatando ausência de significância nas populações de 


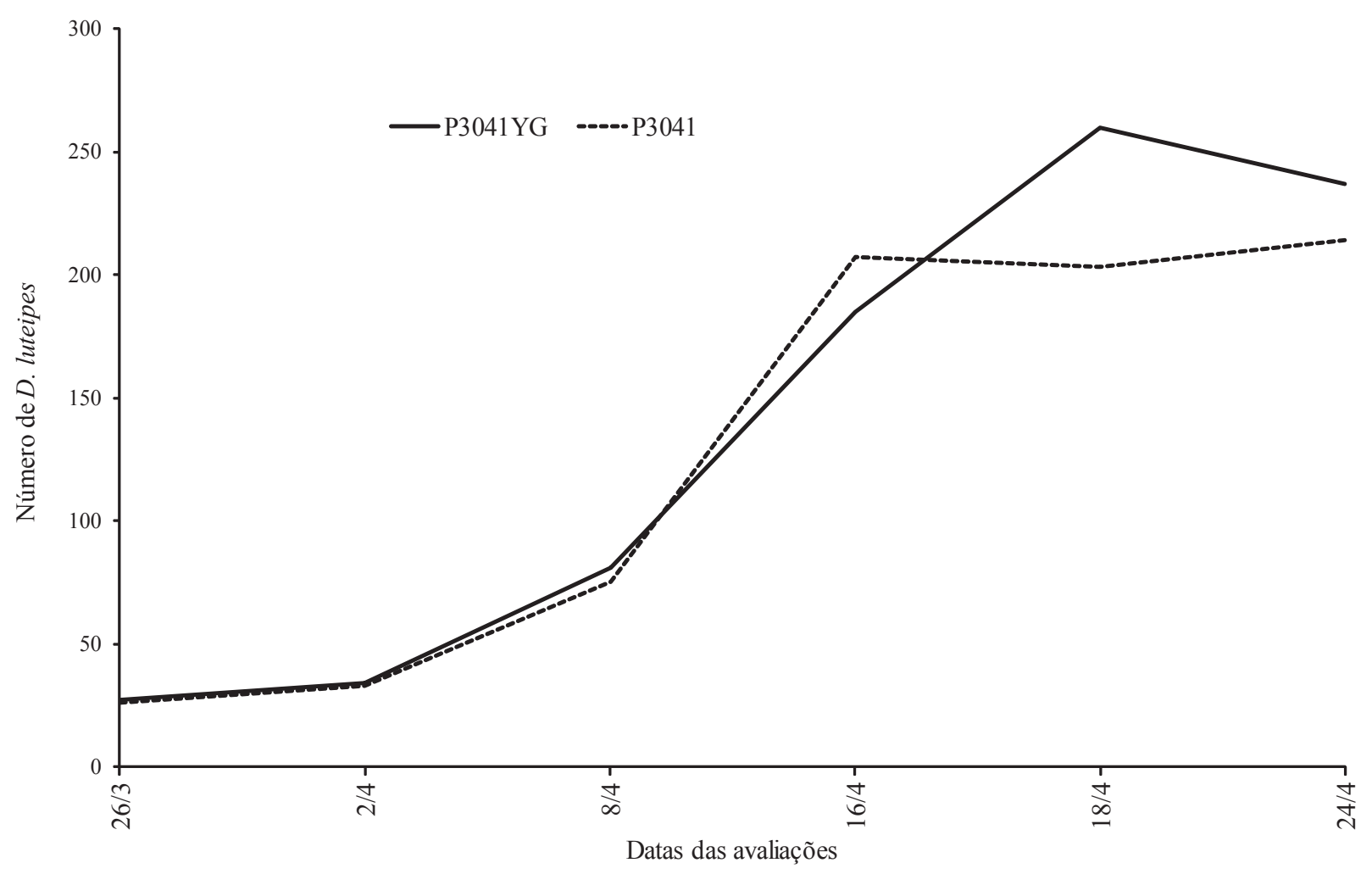

FIGURA 2. Número de D. luteipes em todas as parcelas dos híbridos de milho P 3041 e P 3041YG cultivados na safrinha de 2009, em Rio Verde, GO.

"tesourinha" (Dermaptera: Forficulidae), "joaninhas" (Coleoptera: Coccinellidae), "percevejo-pirata" (Coleoptera: Anthocoridae), carabídeos (Coleoptera: Carabidae), cicindelídeos (Coleoptera: Cicindelidae) e aranhas (Araneae), além do parasitismo de ovos de H. zea por Trichogramma spp. (Hymenoptera: Trichogrammatidae), entre os híbridos 7590-Bt11 e Avant-ICP4 (Cry1Ab e VIP3A, respectivamente), em relação aos respectivos genótipos não transgênicos.

$\mathrm{Na}$ análise da ocorrência de $D$. saccharalis, pode-se constatar que a incidência foi baixa, comprovada pela ausência de significância entre o número de internódios brocados e o comprimento das galerias entre os híbridos convencional e transgênico (Tabela 2). Em casos de maior ataque dessa praga, pode-se observar o quebramento de colmos, fato não constatado no ensaio, além da diminuição do enchimento de grãos pela obstrução no fluxo de seiva na planta. Além disso, o ataque pode favorecer a infecção dos colmos e espigas por microorganismos, podendo ocasionar grãos ardidos (Cruz, 2007). A baixa incidência de $D$. saccharalis pode ser justificada pela presença de $D$. luteipes, a qual é eficiente no controle da broca-da-cana, em estádios iniciais de desenvolvimento (Sueldo \& Virla, 2009).

$\mathrm{Na}$ fase final de desenvolvimento do milho, constatou-se que o híbrido convencional apresentou maiores valores de altura de plantas e de inserção da espiga, em relação ao híbrido $B t$ (Tabela 2). Como consequência, obteve-se maior número de 
TABELA 1. Valores médios de nota de sintoma de ataque na planta e pendão e população de lagartas $S$. frugiperda por planta, em híbrido de milho convencional (P 3041) e transgênico Bt (P 3041YG), cultivados na safrinha 2009, em Rio Verde, GO.

\begin{tabular}{|c|c|c|c|c|c|c|}
\hline \multirow{3}{*}{$\begin{array}{c}\text { Data das } \\
\text { avaliações }\end{array}$} & \multicolumn{4}{|c|}{ Nota de sintoma de ataque } & \multirow{2}{*}{\multicolumn{2}{|c|}{$\begin{array}{l}\text { Número deS. frugiperda por } \\
\text { planta }^{1}\end{array}$}} \\
\hline & \multicolumn{2}{|c|}{ Planta $^{1}$} & \multicolumn{2}{|c|}{ Pendão ${ }^{1}$} & & \\
\hline & Bt & Convencional & Bt & Convencional & $B t$ & Convencional \\
\hline $26 / 03(8)^{2}$ & $0,66 \mathrm{a}$ & $5,08 \mathrm{~b}$ & -3 & - & $0,16 \mathrm{a}$ & $1,37 \mathrm{~b}$ \\
\hline 02/04 (34) & $1,29 \mathrm{a}$ & $5,04 \mathrm{~b}$ & - & - & $0,08 \mathrm{a}$ & $0,90 \mathrm{~b}$ \\
\hline 08/04 (41) & $0,79 \mathrm{a}$ & $3,45 \mathrm{~b}$ & - & - & $0,04 \mathrm{a}$ & $0,30 \mathrm{~b}$ \\
\hline $16 / 04(55)$ & $1,25 \mathrm{a}$ & $5,79 \mathrm{~b}$ & $0,29 \mathrm{a}$ & $0,95 \mathrm{~b}$ & $0,41 \mathrm{a}$ & $1,58 \mathrm{~b}$ \\
\hline $18 / 04(57)$ & $1,54 \mathrm{a}$ & $4,91 \mathrm{~b}$ & $0,41 \mathrm{a}$ & $1,79 \mathrm{~b}$ & $0,37 \mathrm{a}$ & $1,45 \mathrm{~b}$ \\
\hline 24/04 (63) & $1,70 \mathrm{a}$ & $3,41 \mathrm{~b}$ & $0,00 \mathrm{a}$ & $1,08 \mathrm{~b}$ & $0,20 \mathrm{a}$ & $0,87 \mathrm{~b}$ \\
\hline
\end{tabular}

${ }^{1}$ Médias seguidas de mesma letra, na linha, não diferem entre si pelo teste de t, a $5 \%$ de probabilidade. ${ }^{2}$ Dias após a emergência das plântulas. ${ }^{3}$ Não avaliado.

TABELA 2. Altura de planta e inserção da espiga, número total de internódios, número de internódios até a espiga, internódios brocados, comprimento da galeria, massa de grãos por espiga e rendimento de grãos de híbridos de milho convencional (P3041) e transgênico Bt (P 3041YG), cultivados na safrinha de 2009, em Rio Verde, GO.

\begin{tabular}{|c|c|c|c|}
\hline Características avaliadas & P3041 & $\begin{array}{c}\text { P3041YG } \\
(B t)\end{array}$ & Contraste \\
\hline Altura de planta (m) & $2,15 \mathrm{a}$ & $2,07 \mathrm{~b}$ & $0,08 *$ \\
\hline Altura de espiga (m) & $1,24 \mathrm{a}$ & $1,13 \mathrm{~b}$ & $0,11 *$ \\
\hline Total de internódios & $14,4 \mathrm{a}$ & $13,9 \mathrm{~b}$ & $0,50 *$ \\
\hline Internódio da espiga & $9,9 \mathrm{a}$ & $8,6 \mathrm{~b}$ & $1,30 *$ \\
\hline Internódio brocado & 0,16 & 0,06 & $0,10^{\text {ns }}$ \\
\hline Comprimento da galeria & 0,14 & 0,01 & 0,13 ns \\
\hline Massa de grãos espiga ${ }^{-1}(\mathrm{~g})$ & $120,21 \mathrm{~b}$ & 134,03 a & $-13,82 *$ \\
\hline Rendimento de grãos $\left(\mathrm{kg} \cdot \mathrm{ha}^{-1}\right)$ & $6.033 \mathrm{~b}$ & $6.627 \mathrm{a}$ & $-594 *$ \\
\hline
\end{tabular}

*Significativo pelo teste de $\mathrm{t}$, a $5 \%$ de probabilidade.

internódios e posição superior do internódio da milho Bt. A adoção dessa tecnologia tem promovido espiga. Na avaliação do peso e rendimento de grãos, redução de perdas de rendimento da ordem de $20 \%$, foram constatados maiores valores com o uso do devido ao melhor controle das lagartas que atacam 
o milho, além de proporcionar redução no uso de inseticidas (Bobrowski et al., 2003), destacando, que nessa pesquisa, não foi realizada a aplicação de inseticida.

$\mathrm{O}$ entendimento dos fatores bióticos e/ou abióticos que interferem na dinâmica populacional de $S$. frugiperda é de extrema importância para a adoção de táticas de controle mais eficaz, de forma a permitir a preservação dos inimigos naturais da praga (Figueiredo et al., 2006). A utilização de inseticidas químicos sintéticos, sem quantificar a presença de organismos benéficos na área, pode ocasionar o uso de forma inadequada do produto, e quando apresentar amplo espectro de ação, o inseticida pode também impactar negativamente os inimigos naturais de $S$. frugiperda e de $D$. saccharalis.

\section{Conclusões}

O híbrido de milho transgênico P 3041YG apresentou menor dano causado pela lagarta $S$. frugiperda, maior massa de grãos por espiga e maior rendimento de grãos em relação ao híbrido convencional P 3041.

A variação da população de $D$. luteipes é influenciada pela população de $S$. frugiperda.

\section{Referências}

BOBROWSKI, V. L.; FIUZA, L. M.; PASQUALI, G.; BODANESE-ZANETTINI, M. H. Genes de Bacillus thuringiensis: uma estratégia para conferir resistência a insetos em plantas. Ciência Rural, Santa Maria, v. 34, n. 1, p. 843-850, 2003.

CASTRO, A. L. G; CRUZ, I.; SILVA, I. F.; PAULA, C. de S.; LEAO, M. L.; FERREIRA, T.E.; MENEZES, A. P.de J. Flutuação populacional do parasitóide Eiphosoma vitticole (Cresson) (Hymenoptera: Ichneumonidae) em milho convencional e transgênico $(B t)$. Revista Brasileira de Agroecologia, Cruz Alta, v. 4, n. 2, p. 4341-4344, 2009.

CRUZ, I. A lagarta-do-cartucho na cultura do milho. Sete Lagoas: Embrapa Milho e Sorgo, 1995. 45 p. (Embrapa Milho e Sorgo. Circular Técnica 21).

CRUZ, I.; TURPIN, F. T. Yield impact of larval infestations of the fall armyworm (Lepidoptera: Noctuidae) to midwhorl growth stage of corn. Journal of Economic Entomology, Salt Lake, v. 76, n.2, 10521054, 1983.

CRUZ, I. A Broca da cana de açúcar, Diatraea saccharalis, em milho, no Brasil. Sete Lagoas: Embrapa Milho e Sorgo, 2007. 12 p. (Embrapa Milho e Sorgo. Circular Técnica, 90).

CRUZ, I.; FIGUEIREDO, M. L. C.; SILVA, R. B. Monitoramento de adultos de Spodoptera frugiperda (J. E. Smith) (Lepidoptera: Noctuidade) e Diatraea saccharalis (Fabricius) (Lepidoptera: Pyralidade) em algumas regiões produtoras de milho no Brasil. Sete Lagoas: Embrapa Milho e Sorgo, 2010a. 42 p. (Embrapa Milho e Sorgo. Documentos, 93).

CRUZ, I.; FIGUEIREDO, M. L. C.; SILVA， R. B.; FOSTER, J.E. Efficiency of chemical pesticides to control Spodoptera frugiperda and validation of pheromone trap as a pest management tool in maize crop. Revista Brasileira de Milho e Sorgo, Sete Lagoas, v. 9, n. 2, p. 107-122, 2010b.

DAVIS, F. M.; NG, S. S.; WILLIAMS, W. P. Visual rating scales for screening whorl-stage corn for resistance to fall armyworm. Mississippi: Agricultual and Forest Experiment Station, 1992. 9 p. (Technical Bulletin, 186).

DIEZ-RODRÍGUEZ, G. I.; OMOTO, C. Herança da resistência de Spodoptera frugiperda J. E. Smith 
(Lepidoptera: Noctuidae) a lambda-cialotrina. Neotropical Entomology, Londrina, v. 30, n. 2, p. 311-316, 2001.

FARIAS, P. R. S.; BARBOSA, J. C.; BUSOLI, A. C. Distribuição espacial da lagarta do cartucho, Spodoptera frugiperda J. E. Smith (Lepidoptera: Noctuidae), na cultura do milho. Neotropical Entomology, Londrina, v. 30, n. 4, p. 681-689, 2001.

FERNANDES, O. A.; CARNEIRO, T. R.; Controle biológico de Spodoptera frugiperda no Brasil. In: PINTO, A. de S.; NAVA, D. E.; ROSSI, M. M.; MALERBO-SOUZA, D. T. (Org.). Controle biológico de pragas na prática. Piracicaba: CP 2, 2006. p. $75-82$.

FERNANDES, O. A.; FARIA, M.; MARTINELLI, S.; SCHMIDT, F.; CARVALHO, V. F.; MORO, F. Short-term assessment of Bt maize on non-target arthropods in Brazil. Scientia Agricola, Piracicaba, v. 64, n. 3, p. 249-255, 2007.

FERNANDES, O. D; PARRA, J. R. P; FERREIRA NETO, A.; PÍCOLI, R.; BORGATTO, A. F; DEMÉTRIO, C. G. B. Efeito do milho geneticamente modificado MON810 sobre a lagarta do cartucho Spodoptera frugiperda J. E. SMITH, 19797) (Lepidoptera: Noctuidae). Revista Brasileira de Milho e Sorgo, Sete Lagoas, v. 2, n. 2, p. 25-35, 2003.

FIGUEIREDO, M. L. C.; CRUZ, I.; DIAS, A. M. P.; SILVA, R. B. Ocorrência do parasitoide Chelonus insularis no sul de Minas Gerais associado a lagartas de Spodoptera frugiperda na cultura de milho. Revista Brasileira de Agroecologia, Cruz Alta, v. 4, n. 2, p. 4281-4284, 2009.

FIGUEIREDO, M. L. C.; MARTINS-DIAS, A. M. P.; CRUZ, I. Relação entre a lagarta-do-cartucho e seus agentes de controle biológico natural na produção de milho. Pesquisa Agropecuária Brasileira, Brasília,
DF, v. 41, p. 1693-1698, 2006a.

FIGUEIREDO, M. L. C.; MARTINS-DIAS, A. M. P.; CRUZ, I. Associação entre inimigos naturais e Spodoptera frugiperda (J.E. Smith, 1797) (Lepidoptera: Noctuidae) na cultura do milho. Revista Brasileira de Milho e Sorgo, Sete Lagoas, v. 5 , n. 3 , p. $340-350,2006$ b.

GUERREIRO, J. C.; BERTI FILHO, E.; BUSOLI, A. C. Ocorrência estacional de Doru luteipes na cultura do milho em São Paulo, Brasil. Manejo Integrado de Plagas y Agroecologia, Costa Rica, n. 70, p. 46-49, 2003.

HUANG, F.; BUSCHAMAN, L. L; HIGGINS, R. A.; LI, H. Survival of Kansas dipel-resistant European corn borer (Lepidoptera: Crambidae) on $B t$ and non- $B t$ corn hybrids. Journal of Economic Entomology, Washington, v. 95, n. 3, p. 614-621, 2002.

MAAGD, R. A.; BRAVO, A.; CRICKMORE, N. How Bacillus thuringiensis has evolved specific toxins to colonize the insect world. Trends in Genetics, Cambridge, v. 17, n. 40, p. 193-199, 2001.

MILANO, P.; BERTI FILHO, E., PARRA, J. R. P.; CÔNSOLI, F. L. Influência da temperatura na frequência de cópula de Anticarsia gemmatalis Hubner e Spodoptera frugiperda (J. E. Smith) (Lepidoptera:Noctuidae).NeotropicalEntomology, Londrina, v. 37, n. 5, p. 538-535, 2008.

MOSCARDI, F.; SOUZA, M. L. Baculovírus para o controle de pragas: panacéia ou realidade? Biotecnologia Ciência e Desenvolvimento, Brasília, DF, v. 1, n. 24, p. 22-29, 2002.

PASINI, A.; PARRA, J. R. P.; NAVA, D. E.; BUTNARIU, A. R. Exigências térmicas de Doru lineare Eschs e Doru luteipes Scudder em laboratório. Ciência Rural, Santa Maria, v. 40, n. 7, p. 1562-1568, 2010. PICANÇO, M. C.; GALVAN, T. L.; Galvão, J. C. C.; SILVA, E. C.; GONTIJO, L. M. Intensidades de 
perdas, ataque de insetos-praga e incidência de inimigos naturais em cultivares de milho em cultivo de safrinha. Ciência e Agrotecnologia, Lavras, v. 27, n. 2, p. 339-347, 2003.

SANGOI, L.; SCHMITT, A.; ZANIN, G. C. Área foliar e rendimentos de grãos de híbridos de milho em diferentes populações de plantas. Revista Brasileira de Milho e Sorgo, Sete Lagoas, v. 6, n. 3 p. 263-271, 2007.

SUELDO, G. M. R.; VIRLA, E. G. Datos biológicos de Doru luteipes (Dermaptera: forficulidae) em plantaciones de caña de azúcar y consumo de huevos de Diatraea saccharalis (Lepidoptera: Crambidae) em condiciones de laboratório. Revista de la Sociedad de Entomológica Argentina, Mendoza, v. 68 , n. 3-4, p. 359-363, 2009.
WAQUIL, J. M.; BOREGAS K. G. B.; MENDES S. M. Viabilidade do uso de hospedeiros alternativos como área de refúgio para o manejo da resistência da lagarta-docartucho, Spodoptera frugiperda (J. E. Smith) (Lepidoptera: Noctuidae) no cultivo do milho Bt. Sete Lagoas: Embrapa Milho e Sorgo, 2008. 10 p. (Embrapa Milho e Sorgo. Comunicado Técnico, 160).

WAQUIL, J. M.; VILELA, F. M. F.; FOSTER, J. E. Resistência do milho (Zea mays L.) transgênico (Bt) à lagarta-do-cartucho, Spodoptera frugiperda Smith (Lepidoptera: Noctuidae). Revista Brasileira de Milho e Sorgo, Sete Lagoas, v. 1, n. 3, p. 1-11, 2002. 